BMJ Paediatrics Open

\section{Efficacy of an interventional educational programme in mitigating post-traumatic stress in parents who have witnessed a febrile seizure: a pilot before-and- after study}

To cite: Frascari F, Dreyfus I, Chaix Y, et al. Efficacy of an interventional educational programme in mitigating posttraumatic stress in parents who have witnessed a febrile seizure: a pilot before-and-after study. BMJ Paediatrics Open 2017;1:e000107. doi:10.1136/ bmjpo-2017-000107

\section{- Additional material is} published online only. To view please visit the journal online (http://dx.doi.org/10.1136/ bmjpo-2017-000107).

Received 26 May 2017 Revised 1 November 2017 Accepted 11 November 2017

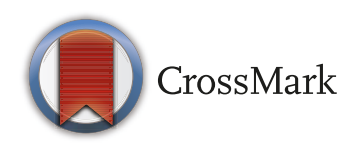

${ }^{1}$ Department of Pediatric Neurology, Children Hospital, Centre Hospitalier Universitaire de Toulouse, Toulouse, France ${ }^{2}$ Department of Dermatology, CHU Larrey, Centre Hospitalier Universitaire de Toulouse, Toulouse, France

${ }^{3}$ Toulouse Neurolmaging Center (TONIC), UMR 1214, Université Toulouse 3 (UT3), Toulouse, Midi-Pyrénées, France

Correspondence to Dr Flora Frascari, Department of Pediatric NeurologyChildren Hospital, Centre Hospitalier Universitaire de ToulouseToulouseFrance; frascari.flora@gmail.com

\section{ABSTRACT}

Objectives To measure post-traumatic stress in parents who have witnessed their child's first simple febrile seizure and to assess the impact of workshops where information is dispensed, proper reactions are demonstrated and dialogue is encouraged on the mitigation of parental stress. Design A pilot before-and-after study, with control group, using self-reported measures from the Impact of Event Scale-Revised.

Setting Data from two French participating centres. Participants A total of 50 parents who witnessed their child's first simple febrile seizure.

Intervention Parents selected themselves into either group 1: attending a workshop (intervention group), or group 2: no further management (control group).

Primary and secondary outcome measures (1) Parental post-traumatic stress was assessed by the Impact of Event Scale-Revised a minimum of 4 weeks after the seizure (before any workshop if applicable). A high risk of developing post-traumatic stress disorder was indicated by a score $\geq 33$. (2) To assess the efficacy of workshops on the mitigation of parental stress, all parents selfcompleted the Impact of Event Scale-Revised a second time at a minimum of 10 weeks after the seizure (after any workshop if applicable).

Results Four weeks after the seizure, $76 \%$ of the total parents presented an Impact of Event Scale-Revised score $\geq 33$. At 10 weeks after the seizure, the scores were 18.1 points lower $(95 \% \mathrm{Cl} 11.66$ to $24.61, \mathrm{P}<0.0001)$ in group 1 versus only 5.51 points lower $(95 \% \mathrm{Cl} 2.76$ to 8.27 , $\mathrm{P}=0.0003$ ) in group 2 (intragroup comparison), and were significantly lower in group 1 compared with group 2 (intergroup comparison), $\mathrm{P}=0.02$.

Conclusions Parents who have witnessed their child's first simple febrile seizure are at high risk of developing post-traumatic stress disorder 4 weeks after the seizure. Our innovative workshops are associated with a significant mitigation of the parental post-traumatic stress.

\section{INTRODUCTION}

Simple febrile seizures are the most common seizures in children $<60$ months and are accompanied by fever of $38^{\circ} \mathrm{C} \quad\left(100.4^{\circ} \mathrm{F}\right)$

\section{What is already known on this topic?}

Febrile seizures can be frightening for parents.

- In management, it is crucial to highlight that they are not life threatening and to distribute information leaflets.

\section{What this study adds?}

More than three out of four parents who have witnessed their child's first simple febrile seizure are at high risk of developing post-traumatic stress disorder.

- Parental post-traumatic stress is mitigated by innovative workshops that dispense information, demonstrate reactions and encourage dialogue.

without central nervous system infection. ${ }^{1}$ They are recognised by healthcare professionals as a benign condition with a good prognosis $^{2}$; however, they can be frightening $^{3-6}$ for parents who may believe that their child is dying. ${ }^{7-10}$ Reassurance, education and distribution of information leaflets are important steps in management. ${ }^{11-13}$ In this context, we developed workshops ${ }^{14} 15$ led by a multidisciplinary medical team, which inform, advise and train the parents in case of seizure recurrence.

As stipulated in the Diagnostic and Statistical Manual of Mental Disorders, Fifth Edition, ${ }^{16}$ post-traumatic stress disorder (PTSD) belongs to a new class of trauma and stressor-related disorders. PTSD requires exposure to actual or threatened death, in which the individual can directly experience the event, witness it in person or learn that it occurred to a close family member. Persons with PTSD present four clusters of specific PTSD symptoms (intrusion, avoidance, 


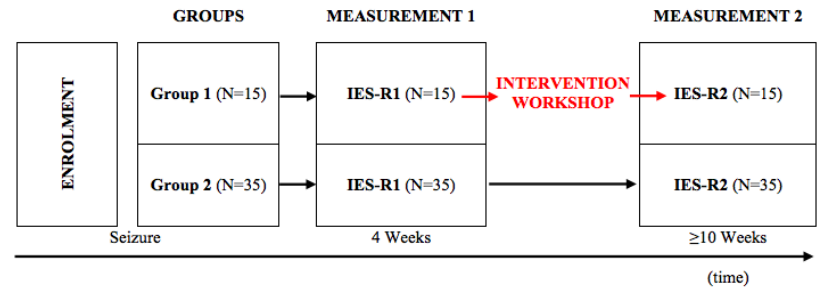

Figure 1 Study design. IES-R, Impact of Event ScaleRevised.

negative alterations in cognition and mood, alterations in arousal and reactivity) for $>1$ month, and can be screened by the Impact of Event Scale-Revised (IES-R). ${ }^{17}$

The aims of this study were to investigate (1) the prevalence of post-traumatic stress-related symptoms in a cohort of parents who witnessed their child's first simple febrile seizure and (2) assess the efficacy of workshops on the mitigation of parental stress.

\section{PATIENTS AND METHODS}

\section{Study design and participants}

We designed a pilot before-and-after cross-sectional study, with a control group (details regarding study design are shown in figure 1). We collected verbal informed consent of the parents after they had been accurately informed, orally and by written information, of the purpose, methods, risks, benefits and alternative to the research. As the research focused on parental stress, only the participating parent consented. Parents who had witnessed their child's first simple febrile seizure were enrolled after their child received standard care in the emergency room and were followed prospectively. Inclusion criteria were (1) mothers or fathers $\geq 18$ years old, who had witnessed this child's first episode of simple febrile seizure, (2) only one parent per family could be included. Exclusion criteria were as follows: (1) grandparents or other relatives of the child, (2) second episode of simple febrile seizure, (3) complex febrile seizures or non-febrile seizures and (4) parental psychiatric medical history. Overall two sites enrolled patients from France: site 1 was the Hopital des Enfants de Toulouse, Toulouse, France, and site 2 was the Hopital General de Montauban, Montauban, France (online supplementary table). Among the parents some volunteered to follow our educational programme (group 1) and some did not (group 2). At 4 weeks after the seizure, parents were invited to fill out a standardised questionnaire to record demographic characteristics of the parent and the child, job/training in healthcare of the parent, previous experience of witnessing somebody else's seizure and opportunity for the parent to discuss their experience with a healthcare practitioner. Charts from the emergency room provided relevant information regarding the characteristics of the seizure (duration, loss of contact and muscular tone abnormalities). Parents were not involved in the design of this research, but it builds on previous qualitative research exploring the experiences and beliefs of the parents. ${ }^{18} 19$

\section{Measurement of post-traumatic stress symptoms: Impact of Event Scale-Revised (IES-R)}

The French IES-R has demonstrated good psychometric properties, a robust internal consistency with alpha coefficients ranging from 0.81 to 0.93 for its three subscales and total score, and a satisfactory test-retest reliability with correlation coefficients ranging from 0.71 to 0.76 for its three subscales and total score. ${ }^{20}$ The IES-R comprises 22 items that measure symptoms of intrusion, avoidance and numbing, and hyperarousal. Participants rate on a 5-point Likert scale the extent to which each item applied to their experience during the preceding 7 days. Total score on the IES-R ranges between 0 and 88 . Interpretation of the IES-R scores were realised as recommended: a score between 1 and 11 indicated a small amount of post-traumatic stress symptoms, a score between 12 and 32 indicated a great amount of post-traumatic stress symptoms, and a score $\geq 33$ indicated the possibility of PTSD ${ }^{20}$ We also calculated the percentage of parents presenting a score $\geq 37$ as it has been reported as a high enough score to suppress immune system functionning. ${ }^{21}$ In patients with acute PTSD experience symptoms for $<3$ months; chronic PTSD results in symptoms lasting $\geq 3$ months. ${ }^{1722} 23$

For all parents, the validated French version of the IES-R was self-completed at two-time points: at least 4 weeks following the seizure for the first IES-R (IES-R1) and at least 10 weeks following the seizure for IES-R2. Once completed by the parents, IES-R assessments were transmitted to our department via email or mail. We used phone calls to remind parents to return their IES-R assessments. All parents in group 1 completed a workshop between the IES-R1 and IES-R2 assessments.

\section{Workshops}

Small group workshops were subdivided into three, 1-hour blocks. The first hour was used to dispense general information; presentation slides were colourful and easy to read (figure 2). The second hour was dedicated to demonstrations of how to react in case of recurrence using a medical mannequin. The last hour was reserved for a question/answer session. Workshops were led by a paediatrician specialised in paediatric neurology, two nurses and a psychologist. An anonymous standardised questionnaire was distributed to each parent at the end of the third hour, and was completed onsite. Using visual analogue scales from 0 to 10 , parents recorded a self-assessment on the following items: general satisfaction regarding the workshops, theoretical knowledge on seizures, ability to react and subjective stress level before and after the workshops.

\section{Statistical analysis}

Descriptive attributes were recorded to characterise (1) parents: hospital of origin, age, gender, previous 


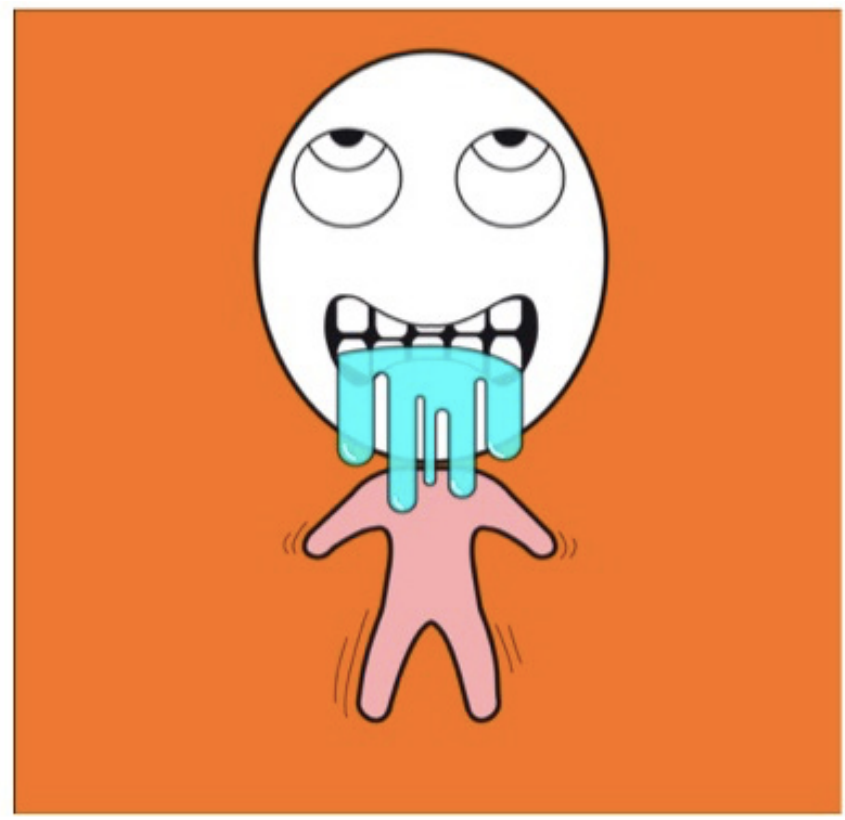

Figure 2 A slide of the presentation during the workshops. Febrile seizures: what did you see?

experience of witnessing a seizure of another child or someone else and job/training related to healthcare; (2) children: age; and (3) seizures: duration, loss of contact and muscle tone abnormalities. The comparability of the two groups was assessed using a MannWhitney test for continuous values (parental age, child age, IES-R1 value, delay convulsion-IES-R1, delay IES-R1 to IES-R2 and delay convulsion-IESR-2) and a Fisher exact test for categorical values (gender, previous experience of witnessing a seizure and occupation related to healthcare).

Correlations between IES-R1 scores and the age of the child and the age of the parents were analysed using a Pearson correlation test. Additionally, the mother and father's IES-R1 scores were compared using a Mann-Whitney test. To isolate the specific effect of a workshop on the IES-R value, and to differentiate it from the effect of elapsed time, the statistical analysis included (1) an intergroup comparison of IES-R2 scores in group 1 versus group 2, using a Mann-Whitney test, and (2) an intragroup comparison of IES-R2 scores versus IES-R1 scores in groups 1 and 2, using a paired samples t-test. A conventional two-way analysis of variance was used to assess for the effect of group selection over time in evaluating the IES-R1-IES-R2 score reduction. Comparison of visual analogic scale values before and after workshop for parental theoretical knowledge on seizure, parental ability to react and parental subjective stress level were realised using a paired samples t-test. $\mathrm{P}$ values $<0.05$ were considered significant. All statistical analyses were performed using GraphPad Prism V.6.0.

\begin{tabular}{|c|c|c|c|c|}
\hline Feature & All $(n=50)$ & $\begin{array}{l}\text { Group } 1 \\
(n=15)\end{array}$ & $\begin{array}{l}\text { Group } 2 \\
(n=35)\end{array}$ & $P$ value \\
\hline \multicolumn{5}{|l|}{ Parents } \\
\hline $\begin{array}{l}\text { Age (year), } \\
\text { mean (SD) }\end{array}$ & 35 (5) & 36 (5) & $35(5)$ & $0.27^{*}$ \\
\hline Gender & & & & $0.85 \dagger$ \\
\hline Man & $11(22 \%)$ & $3(20 \%)$ & $8(23 \%)$ & \\
\hline Woman & 39 (78\%) & 12 (80\%) & 27 (77\%) & \\
\hline \multicolumn{5}{|l|}{ Children } \\
\hline $\begin{array}{l}\text { Age (year), } \\
\text { mean (SD) }\end{array}$ & $2(1)$ & $3(1)$ & $2(1)$ & $0.65^{*}$ \\
\hline
\end{tabular}

*Based on Mann-Whitney test.

†Based on Fisher test.

\section{RESULTS \\ Descriptive characteristics}

A total of 189 parents were eligible during the inclusion period of 6 months (details regarding parent demographic characteristics, as well as age of their child are summarised in table 1 ). Only 74 parents were approached, with 50 parents consented. All consenting parents participated in each study element, with a total of 50 available for further analysis. Of these 50 parents, roughly $80 \%$ were woman (mothers). Groups 1 and 2 were comparable in term of age and gender of parents, parental previous experience of witnessing a seizure, parental occupation related to healthcare, age of the child and characteristics of the seizure. Eight per cent of the total parents (7\% in group $1 \%$ and $9 \%$ in group 2) had witnessed a seizure previously (due to their job in the healthcare system or because a sibling had seized previously). Roughly $14 \%$ of the parents (13\% in group 1 and $14 \%$ in group 2) had a job or professional training related to healthcare. Only one mother who belonged to group 2 had visited a therapist to discuss her stress symptoms. Children had an average age of 2 years, and all presented a simple febrile seizure. All children had been administered care by a paediatrician or emergency room doctor after the convulsion.

\section{Prevalence of post-traumatic stress symptoms}

Groups 1 and 2 were comparable in term of (1) IES-R1 scores $(\mathrm{P}=0.47),(2)$ delay between seizure and IES-R1 $(\mathrm{P}=0.18)$, (3) delay between IES-R1 and IES-R2 $(\mathrm{P}=0.18)$ and (4) delay between seizure and IES-R2 $(\mathrm{P}=0.10)$ (table 2). First assessment happened at least 4 weeks after the seizure. Of the 50 parents included, $76 \%$ presented an IES-R1 score $\geq 33$, and $24 \%$ presented a score comprised between 12 and 32; none of the parents presented an IES-R1 strictly inferior to 12 . Of interest, $60 \%$ of all parents presented an IES-R1 score $>37$. The minimum elapsed time between the seizure and IES-R1 was 33 days. For 45 parents, this period was $<3$ months after the seizure, with $68 \%$ having an IES-R1 $\geq 33$, and placing them at high risk of acute PTSD. For five parents, 
Table 2 IES-R scores

\begin{tabular}{|c|c|c|c|c|}
\hline Variable & $\begin{array}{l}\text { All } \\
(n=50)\end{array}$ & $\begin{array}{l}\text { Group } 1 \\
(n=15)\end{array}$ & $\begin{array}{l}\text { Group } 2 \\
(n=35)\end{array}$ & P value \\
\hline IES-R1, mean (SD) & $42(16)$ & $44(20)$ & $41(14)$ & $0.47^{*}$ \\
\hline Score $\geq 33$ & & $11(73 \%)$ & $27(77 \%)$ & \\
\hline $12 \leq$ Score $<33$ & & $4(27 \%)$ & $8(23 \%)$ & \\
\hline IES-R2, mean (SD) & $32(13)$ & $26(13)$ & $35(14)$ & $0.02^{*}$ \\
\hline Score $\geq 33$ & & $4(27 \%)$ & $23(66 \%)$ & \\
\hline $12 \leq$ Score $<33$ & & $8(53 \%)$ & $10(28 \%)$ & \\
\hline Score $<12$ & & $3(20 \%)$ & $2(6 \%)$ & \\
\hline Duration from seizure to IES-R1, mean in days (SD) & $54(20)$ & $57(17)$ & $53(21)$ & $0.18^{*}$ \\
\hline Duration from IES-R1 to IES-R2, mean in days (SD) & $69(38)$ & $80(38)$ & $64(37)$ & $0.18^{*}$ \\
\hline Duration from seizure to IES-R2, mean in days (SD) & $123(50)$ & $136(50)$ & $117(50)$ & $0.10^{*}$ \\
\hline
\end{tabular}

IES-R1 was assessed 4 weeks after the seizure (before any workshop if applicable), and IESR-2 was assessed at a minimum of 10 weeks after the seizure (after any workshop if applicable).

*Based on Mann-Whitney test.

IES-R, Impact Event Scale-Revised.

the period was $>3$ months, with $80 \%$ having an IESR1 $\geq 33$, and placing them at high risk of chronic PTSD. We did not find significant correlation between IES-R1 scores and the age of the child ( $\mathrm{R}$ de Pearson $(95 \% \mathrm{CI})=-0.09$ $(-0.36$ to 0.19$), \mathrm{P}=0.54)$ or the age of the parents ( $\mathrm{R}$ de Pearson $(95 \% \mathrm{CI})=-0.11(-0.37$ to 0.18$), \mathrm{P}=0.46)$. We also note that no significant difference occurred between mother and father's IES-R scores $(\mathrm{P}=0.3)$.

\section{Evolution of IES-R score and effect of the workshops}

In the total population, IES-R2 scores were always lower than IES-R1 scores $(\mathrm{P}<0.0001)$ (table 3$)$. A significant diminution of the IES-R2 versus IES-R1 scores was also found in each group (intragroup comparison). However, attending a workshop allowed for a greater diminution of stress symptoms: in group 1, IES-R2 scores were 18.1 points lower than IES-R1 scores (95\% CI 11.66 to 24.61, $\mathrm{P}<0.0001$ ); group 2 had IES-R2 scores that were only 5.51 points lower than IES-R1 scores (95\% CI 2.76 to 8.27, $\mathrm{P}=0.0003$ ) (table 3, figure 3). IES-R2 scores were significantly lower in group 1 compared with group 2 (intergroup comparison) ( $\mathrm{P}=0.02$, figure 3$)$. A two-way analysis of variance yielded a significant effect for the workshop

Table 3 Analysis of the evolution of the IESR scores within total population and each group

\begin{tabular}{lcc}
\hline \multicolumn{3}{c}{ IES-R scores evolution analyses (paired samples t-test) } \\
\hline & $\begin{array}{l}\text { Difference of mean scores } \\
\text { IES-R1 vs IES-R2 }\end{array}$ & P value \\
\hline Total population & $9.3(95 \% \mathrm{Cl}(6.22$ to 12.39$))$ & $<0.0001$ \\
Group 1 & $18.13(95 \% \mathrm{Cl}(11.66$ to 24.61$))$ & $<0.0001$ \\
Group 2 & $5.51(95 \% \mathrm{Cl}(2.76$ to 8.27$))$ & 0.0003 \\
\hline
\end{tabular}

IES-R1 was assessed 4 weeks after the seizure (before any workshop if applicable), and IES-R2 was assessed at a minimum of 10 weeks after the seizure (after any workshop if applicable). IES-R, Impact of Event Scale-Revised. attendance; the average reduction of score was significantly higher for parents who attended a workshop than for the controls $(\mathrm{P}=0.04)$. The effect of time was non-significant $(\mathrm{P}=0.15)$.

\section{Satisfaction and self-evaluation of parents at the end of the} workshops

On average, parents graded their satisfaction to our workshops with a 9.3/10. Their knowledge and ability to react improved, while their subjective stress level decreased (table 4).

\section{DISCUSSION}

To the best of our knowledge, this study is the first to study PTSD-related symptoms in parents that have witnessed their child's febrile seizure. These PTSD-related symptoms are very common, with $76 \%$ of all parents being at risk of developing PTSD. An interventional and educational programme constituted of workshops significantly decreased parental stress. This programme was highly

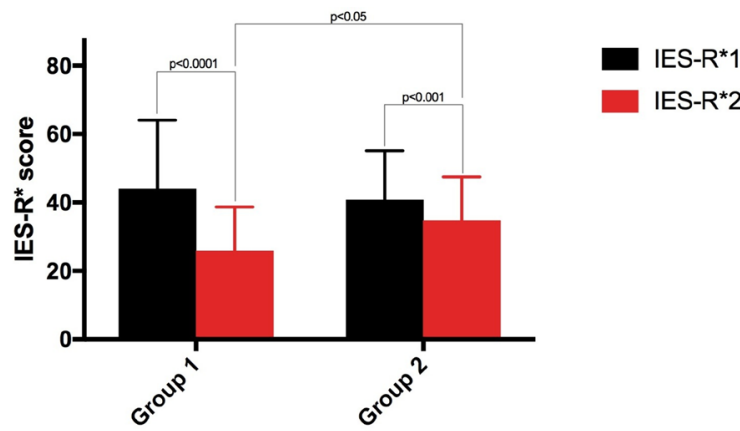

*Impact Event Scale-Revised. IES-R1 was assessed 4 weeks after the seizure (before any workshop if applicable), and IESR-2 was assessed at a minimum of 10 weeks after the seizure (after any workshop if applicable).

Figure 3 IES-R score analyses (intragroup and intergroup). IES-R, Impact of Event Scale-Revised. 
Table 4 Parents' self-evaluation before vs after workshop, using a scale from 0 to 10

\begin{tabular}{lllr}
\hline & Before workshop & After workshop & $\begin{array}{l}\text { Difference of mean scores VAS1 vs VAS2 } \\
\text { (P value) }\end{array}$ \\
\hline $\begin{array}{l}\text { Knowledge: } \\
\text { median (min-max) }\end{array}$ & $3(0-7)$ & $8(6-10)$ & $4.8(95 \% \mathrm{Cl} 4.04$ to 5.56$)(<0.0001)$ \\
$\begin{array}{l}\text { Ability to react: } \\
\text { median (min-max) }\end{array}$ & $5(1-10)$ & $8(6-10)$ & $3(95 \% \mathrm{Cl} 1.55$ to 4.45$)(0.0006)$ \\
$\begin{array}{l}\text { Stress level: } \\
\text { median (min-max) }\end{array}$ & $8(4-9)$ & $4(1-8)$ & $-2.93(95 \% \mathrm{Cl}-3.86$ to -2.01$)(0.0001)$ \\
\hline
\end{tabular}

VAS1 was assessed before workshop and VAS2 was assessed after workshop.

VAS: visual analogue scale.

appreciated by the participants, improved their knowledge and increased their ability to react.

The results of the study are novel; however, we acknowledge several limitations. First, the small number of patients included suggests the necessity to confirm the results in larger samples. Despite our effort to inform the emergency room teams about the study, only $40 \%$ of parents who visited the emergency room for first simple febrile seizure were approached. This can be explained because in an emergency room setting, doctors have limited time to dedicate to each family. This study could be repeated in coordination with paediatricians in private practice to increase the number of participants. Second, the samples we obtained may not be representative of the population intended to be analysed because parents self-selected themselves to the intervention or comparison group. However, both groups were comparable in terms of IES-R1 scores and demographic characteristics; thus, the self-selection did not seem to affect the initial stress or the demographic repartition among the groups. Third, we enrolled mostly mothers $(80 \%)$ who could have different psychological profiles compared with fathers, which could have slightly modified the initial IES-R scores or the response to our intervention. But this predominant feminine representation was homogeneous among the groups, and thus did not alter the comparison between the two groups. Also, this feminine ratio is representative of the parents taking their child to the emergency room in Toulouse. ${ }^{24}$ Fourth, group 1 was only composed of parents from site 1 and group 2 mostly of parents from site 2 . We hypothesise that this occurred because the workshops were geographically located on site 1 , and further (at about 40 min driving distance) from site 2; this seems to have dissuaded most parents from group 2 to register for workshops. This difference in the recruiting centre can be questionable as management of parents could have been different at the two sites. However, we assumed that paediatric simple febrile seizure is a well-known entity so that the care and information given to parents was standardised, and thus similar between both groups. Based on oral conversations with the parents, the small number of parents included in group 1 could also be due to workshops being scheduled in the afternoons, making it difficult for most parents who have a daytime job to attend.

Despite the small number of patients included, all of them participated in every step of the study. We believe this can be explained (1) because we followed up with parents via phone calls as a reminder for them to send back their IES-R assessments, and (2) because parents were very supportive of the study, as shown in the survey responses. The parents were satisfied with the medical team because they showed personal concern for their stress.

In all groups, and even in group 2, IES-R2 scores were always lower than IES-R1 scores. The majority of adults with post-traumatic stress symptoms do recover over the course of months or years without receiving any form of treatment. ${ }^{25}{ }^{26}$ However, the greater reduction of the scores in group 1 highlights the efficacy of the workshops in decreasing parental stress.

A previous study, conducted from an anthropological point of view, had gathered the parental mental representations regarding the word 'seizure', and the actual experience of a seizure ${ }^{18}$; the representations and knowledge of the parents were poor, referring to the old beliefs since antiquity. ${ }^{19}$ This seemed to directly contribute to the intensity of the parental stress. In this previous study, parental representations did not differ according to gender $^{27}$ nor socioeconomic status. ${ }^{19}$

Even though all parents received reassurance and information leaflets from the emergency room doctors before returning home, parental stress remained high and parental knowledge remained low. ${ }^{28-31}$ We hypothesise that this information was delivered during the acute period when the parent was too scared to be able to receive and incorporate the medical reassurance. Workshops organised in a dedicated time a few weeks after the seizure would provide a more efficient mechanism for the parents to be informed and reassured. We note that a third of patients can present a major depressive disorder after a traumatic event. ${ }^{32}$ These workshops represent a first step towards a multidisciplinary approach in paediatrics; however, specific psychological interventions that specifically treat trauma remain critical. Future work will establish a connection between our paediatric team and 
psychologists/psychiatric experts. We expect this to lead to further prevention and/or treatment of PTSD-related symptoms in parents who have witnessed their child's first simple febrile seizure.

\section{CONCLUSIONS}

Our results demonstrate that parents who witness their child's first simple febrile seizure present a high risk of developing PTSD. Despite the limitations of our pilot study, these findings are particularly relevant because understanding the impact of a simple febrile seizure on parental psychological health is an active area for improvement in attention, assessment and management in paediatrics. An interventional and educational programme, such as our multidisciplinary workshops, aids in parental psychological health by giving access to medical information and training, and encouraging communication among parents and with healthcare providers. Our results provide a path forward for the development of multidisciplinary workshops on simple febrile seizure in leading paediatric centres.

Acknowledgements The authors thank Alan Bradley and Dr Dustin Carroll for their assistance with English language.

Contributors FF: participated in design and coordination of the study, contributed to the acquisition and interpretation of data, participated in statistical analyses, drafted the initial manuscript and approved the final submitted manuscript. ID: performed the statistical analyses, co-wrote the manuscript and approved the final submitted manuscript. YC: contributed to the acquisition and interpretation of data, co-wrote the manuscript and approved the final submitted manuscript. CT-C: co-designed and co-coordinated the study, contributed to the acquisition and interpretation of data, co-wrote the manuscript and approved the final submitted manuscript.

Competing interests None declared.

Ethics approval Ethics Committee of Toulouse University Hospital.

Provenance and peer review Not commissioned; externally peer reviewed.

Open Access This is an Open Access article distributed in accordance with the Creative Commons Attribution Non Commercial (CC BY-NC 4.0) license, which permits others to distribute, remix, adapt, build upon this work non-commercially, and license their derivative works on different terms, provided the original work is properly cited and the use is non-commercial. See: http://creativecommons.org/ licenses/by-nc/4.0/

(c) Article author(s) (or their employer(s) unless otherwise stated in the text of the article) 2017. All rights reserved. No commercial use is permitted unless otherwise expressly granted.

\section{REFERENCES}

1. Guidelines for epidemiologic studies on epilepsy. Commission on Epidemiology and Prognosis, International League Against Epilepsy. Epilepsia 1993;34:592-6.

2. Patel N, Ram D, Swiderska N, et al. Febrile seizures. BMJ 2015;351:h4240.

3. Balslev T. Parental reactions to a child's first febrile convulsion. A follow-up investigation. Acta Paediatr Scand 1991;80:466-9.

4. Kolahi AA, Tahmooreszadeh S. First febrile convulsions: inquiry about the knowledge, attitudes and concerns of the patients' mothers. Eur J Pediatr 2009;168:167-71.
5. Chiou HH, Hsieh LP. Parenting stress in parents of children with epilepsy and asthma. J Child Neurol 2008;23:301-6.

6. Jones T, Jacobsen SJ. Childhood febrile seizures: overview and implications. Int J Med Sci 2007:4:110-4.

7. Rutter N, Metcalfe DH. Febrile convulsions--what do parents do? $\mathrm{Br}$ Med J 1978;2:1345-6.

8. Baumer JH, David TJ, Valentine SJ, et al. Many parents think their child is dying when having a first febrile convulsion. Dev Med Child Neurol 1981;23:462-4.

9. van Stuijvenberg M, de Vos S, Tjiang GC, et al. Parents' fear regarding fever and febrile seizures. Acta Paediatr 1999;88:618-22.

10. Flury T, Aebi $C$, Donati F. Febrile seizures and parental anxiety: does information help? Swiss Med Wkly 2001;131:556-60.

11. Paul F, Jones MC, Hendry C, et al. The quality of written information for parents regarding the management of a febrile convulsion: a randomized controlled trial. J Clin Nurs 2007;16:2308-22.

12. O'Hara KA. First aid for seizures: the importance of education and appropriate response. J Child Neurol 2007;22:30S-7.

13. Simple febrile convulsions in children: explain and reassure the parents. Prescrire Int 2002:11:18-20.

14. Huang MC, Liu CC, Chi YC, et al. Parental concerns for the child with febrile convulsion: long-term effects of educational interventions. Acta Neurol Scand 2001;103:288-93.

15. Shore CP, Perkins SM, Austin JK. The Seizures and Epilepsy Education (SEE) program for families of children with epilepsy: a preliminary study. Epilepsy Behav 2008;12:157-64.

16. American Psychiatric Association., American Psychiatric Association. DSM-5 Task Force. Diagnostic and statistical manual of mental disorders: DSM-5. 5th ed. Washington D.C, 2013.

17. Creamer M, Bell R, Failla S. Psychometric properties of the Impact of Event Scale - Revised. Behav Res Ther 2003;41:1489-96.

18. Tison-Chambellan C, Fine A, Cances C, et al. [Anthropological approach to current parental perceptions of children's seizures]. Arch Pediatr 2013;20:1075-82.

19. Chambellan-Tison $C$, Fine $A$, Cancès $C$, et al. [Seizures and epilepsy: popular thinking and beliefs from antiquity to the 19th century]. Arch Pediatr 2010;17:1259-63.

20. Brunet A, St-Hilaire A, Jehel L, et al. Validation of a French version of the impact of event scale-revised. Can J Psychiatry 2003;48:56-61.

21. Kawamura N, Kim Y, Asukai N. Suppression of cellular immunity in men with a past history of posttraumatic stress disorder. Am J Psychiatry 2001;158:484-6.

22. Horowitz M, Wilner N, Alvarez W. Impact of Event Scale: a measure of subjective stress. Psychosom Med 1979;41:209-18.

23. Joseph S. Psychometric evaluation of Horowitz's Impact of Event Scale: a review. J Trauma Stress 2000;13:101-13.

24. Allenou $C$, Olliac B, Bourdet-Loubère $S$, et al. Symptoms of traumatic stress in mothers of children victims of a motor vehicle accident. Depress Anxiety 2010;27:652-7.

25. Breslau N, Kessler RC, Chilcoat HD, et al. Trauma and posttraumatic stress disorder in the community: the 1996 Detroit Area Survey of Trauma. Arch Gen Psychiatry 1998;55:626-32.

26. Morina N, Wicherts JM, Lobbrecht $\mathrm{J}$, et al. Remission from post-traumatic stress disorder in adults: a systematic review and meta-analysis of long term outcome studies. Clin Psychol Rev 2014;34:249-55.

27. Parmar RC, Sahu DR, Bavdekar SB. Knowledge, attitude and practices of parents of children with febrile convulsion. $J$ Postgrad Med 2001;47:19-23.

28. Huang MC, Liu CC, Huang CC. Effects of an educational program on parents with febrile convulsive children. Pediatr Neurol 1998:18:150-5.

29. Bavdekar SB, Ghule R, Jadhav S. Healthcare-seeking behavior after seizures in children. Indian J Med Sci 2008;62:331-5.

30. Hirfanoglu T, Serdaroglu A, Cansu A, et al. Do knowledge of, perception of, and attitudes toward epilepsy affect the quality of life of Turkish children with epilepsy and their parents? Epilepsy Behav 2009;14:71-7.

31. Okumura A, Watanabe K. Questionnaire survey on the understanding of epilepsy among non-medical persons. Pediatr Int 2008;50:319-21.

32. Ducrocq F, Vaiva G, Cottencin O, et al. [Post-traumatic stress, post-traumatic depression and major depressive episode: literature]. Encephale 2001;27:159-68. 